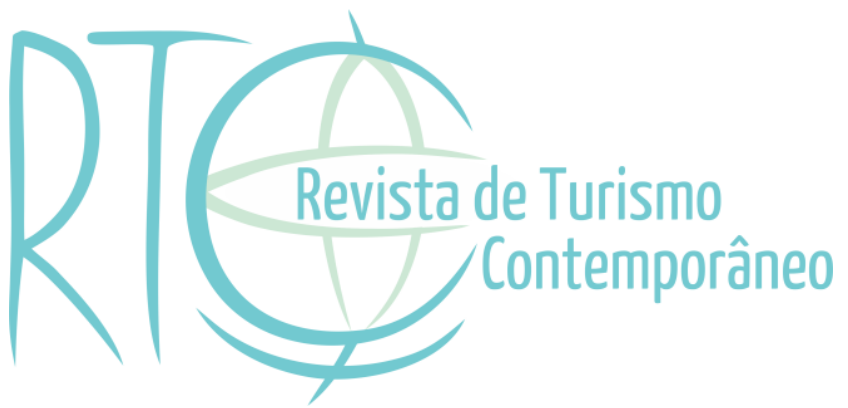

\title{
Mário Carlos Beni: contribuição para o estudo do Turismo
}

Mário Carlos Beni: Contribution to the study of tourism

\author{
Aylana Laíssa Medeiros Borges \\ Mestre em Turismo pela Universidade Federal do Rio Grande do Norte -UFRN. Natal/RN, \\ Brasil \\ E-mail: aylanalaissa@hotmail.com
}

Gilmara Barros da Silva

Mestre em Turismo pela Universidade Federal do Rio Grande do Norte- UFRN. Natal/RN, Brasil

E-mail: gilmarabarross@gmail.com

Artigo recebido em: 24.03.2015

Artigo aprovado em: 19.05. 2015 


\title{
RESUMO
}

O presente artigo versa acerca das contribuições do autor Mário Carlos Beni para o estudo do turismo. Teve como objetivo compreender e reunir os aportes mais fundamentais dados pelo brasileiro aos estudos na área de turismo. A metodologia utilizada foi baseada na abordagem qualitativa, tendo o referido estudo um caráter exploratório-descritivo. Destaca-se que se utilizou ainda do questionário como instrumento de coleta de dados. A partir da realização desse estudo, verificou-se que é de Beni a autoria do livro "Análise Estrutural do Turismo" que no Brasil se consagrou como obra de referência nos cursos formativos em turismo. E constatou-se também que esta célebre persona influenciou sobremaneira a práxis turística, bem como os estudos em turismo á luz do paradigma sistêmico e em relevante perspectiva holística e interdisciplinar.

Palavras-chave: Mário Carlos Beni. Estudo. Turismo.

\begin{abstract}
This research aims to comprehend and assemble the most fundamental contributions to the area of tourism made by Brazilian Mario Carlos Beni. Through bibliographic and eletronic research, as well as the application of interviews, in a descriptive and exploratory qualitative approach, the following information about the author were collected: academic background; professional experience; academic texts related to tourism; major paradigmatic influences present in his publications; legacy to tourism studies. It is noteworthy that Beni is the author of "Análise Estrutural do Turismo" (what could be translated to "Structural Analysis of Tourism") that was consecrated, in Brazil, as a reference book on the formative courses in Tourism. This renowned persona extraordinarily influenced the touristic práxis, as well as tourism studies in the light of the systemic paradigm and in a relevant holistic and interdisciplinary perspective.
\end{abstract}

Keywords: Mário Carlos Beni. Study. Tourism. 


\section{INTRODUÇÃO}

O estudo do turismo tem se realizado considerando diferentes áreas do conhecimento. Por isso têm-se várias interpretações da atividade turística que podem ser evidenciadas de acordo com a área e formação dos autores que estudam o turismo. Uma vez que, por exemplo, os economistas o estudam como atividade geradora de benefícios econômicos e os sociólogos que estudam como uma atividade que envolve a interação social e troca cultural entre os indivíduos.

Ainda se referindo as contribuições para o estudo e teoria do turismo, têm-se autores como Bertalanffy (1968) com a Teoria Geral dos Sistemas que influenciara maior parte dos autores que buscaram estudar elementos, conjuntos ou mesmo através de um sistema como forma de entender a atividade turística. Cuervo (1967) e Leiper (1979) com a proposta de construção de um Sistema Turístico, dentre outros, antecederam os estudos de Mário Carlos Beni (1988), esse considerado o autor que melhor evidenciou os conjuntos e subsistemas que interagem entre si e formam a atividade turística.

Assim, este artigo tem como objetivo apresentar e compreender as contribuições mais fundamentais dadas pelo brasileiro Mário Carlos Beni aos estudos na área de turismo. Então, foi preciso sistematizar informações relacionadas à vida e obra de Beni; Identificar suas publicações voltadas ao estudo do turismo; Identificar os principais autores que influenciaram e/ou foram influenciados por ele (no que tange ao estudo do turismo); Apontar as principais contribuições de Beni para o cenário acadêmico do turismo.

De abordagem qualitativa, fez-se necessário a utilização da pesquisa exploratóriodescritiva tendo em vista o levantamento das obras de Beni, bem como a descrição de seus aspectos mais relevantes. Utilizou-se, ainda, entrevista estruturada, por meio de questionário, que foi realizada em dezembro de 2012, via e-mail, com dois importantes autores da área do turismo, dentre eles: Doris Van de Meene Ruschmann e Luiz Gonzaga Godoi Trigo. O intuito da entrevista foi conhecer a opinião destes pesquisadores sobre o legado de Mário Carlos Beni para a práxis e estudos turísticos.

Elucida-se que a escolha dos autores para realização da entrevista neste estudo, deu-se em função das autoras, deste artigo, possuírem familiaridade e acesso as obras de Doris Ruschmann e Luiz Trigo. Tendo em vista o elo desses autores com Beni, é pertinente realçar que Ruschmann foi orientanda de doutorado do mesmo, enquanto Luiz Gonzaga Godoi Trigo esteve ao lado de Mário Carlos Beni em duas bancas de trabalho de conclusão de curso 
(mestrado), em apresentações de trabalhos/seminários, assim como Beni possui uma produção em um livro organizado por Trigo 1 .

Nesse sentido, a seguir serão apresentados os dados acadêmicos de Mário Carlos Beni, seguido das suas principais obras, sua contribuição para o estudo do turismo e as considerações finais a que se chegou esse estudo.

\section{DADOS ACADÊMICOS DE MÁRIO CARLOS BENI}

Nascido em Casa Branca/São Paulo, em 14 de abril de 1938 (Skoob, 2012), Mário Carlos Beni graduou-se em Ciências Jurídicas pela Universidade Federal Fluminense (1968); obteve título de mestre em Ciências Sociais pela Fundação Escola de Sociologia e Política de São Paulo (1981); doutorou-se em Ciências da Comunicação e é Livre Docente em Planejamento e Desenvolvimento Regional pela Universidade de São Paulo (1988) ${ }^{2}$.

Ainda com base nos dados disponíveis no lattes de Beni, destaca-se a vasta experiência dele na área de turismo concentrando seus estudos nas seguintes linhas de pesquisa: Planejamento e Gestão dos Espaços para o Turismo; Planejamento e Gestão das Empresas de Turismo; e Qualificação de Recursos Humanos para Educação e Pesquisa em Turismo.

Em se tratando da vida acadêmica de Beni, sua carreira como docente foi iniciada na Escola de Comunicação e Artes - ECA na Universidade de São Paulo (USP), no ano de 1971, pelo Departamento de Relações Públicas e Propaganda, onde o referido professor passou a ministrar a recém-criada disciplina de "Turismo e Desenvolvimento". (Vida Acadêmica, 2012). Ressalta-se ainda que no ano de 1972, Beni foi designado, pelo então Diretor da ECA, Prof. Dr. Manoel Nunes Dias, para elaborar o plano de implantação do curso de turismo da USP.

Durante sua vida acadêmica, Beni enriqueceu seu currículo com aproximadamente 630 apresentações de trabalhos, incluindo os de popularização de Ciência e Tecnologia (C\&T) em palestras, conferências, painéis e seminários, além de outras produções bibliográficas totalizando 18. Possui 158 participações em bancas incluindo as de Mestrado; Doutorado; Qualificações de Doutorado; Aperfeiçoamento /Especialização; Bancas de conclusão de curso de Graduação; dentre outros tipos de bancas (Plataforma Lattes, 2014).

\footnotetext{
${ }^{1}$ Currículo Lattes. Disponível em: <http://buscatextual.cnpq.br/buscatextual/visualizacv.do?id=K4768219H3>. Acesso em: 13 jun. 2014.

2 Idem 1.
} 
No que se refere à participação de Beni em comissão julgadora de concurso público, de livre docência, de avaliação de cursos e outros tipos de participação, teve-se um total de 20 participações considerando todas essas comissões. Em se tratando de orientações feitas pelo referido autor teve-se um total de 52 orientações, considerando todas feitas em dissertações de Mestrado, teses de Doutorado, monografia de curso de especialização, e trabalho de conclusão de curso (TCC) em cursos de graduação ${ }^{3}$.

Vale destacar ainda, que no lattes do autor Beni encontra-se um total de 31 trabalhos técnicos; 37 participações em entrevistas, mesas redondas, programas e comentários na mídia; 2 prestações de serviço de assessoria e consultoria; 41 textos em jornais de notícias/revistas; e 3 resumos publicados em anais de congressos.

É pertinente salientar que ao observar o lattes do professor Beni, constata-se que dentre as suas orientações de mestrado e doutorado estão os trabalhos desenvolvidos por renomados autores de obras na área de turismo. E que também contribuem para as discussões acerca do fenômeno, tais como Luiz Renato Ignarra (1998), Miguel Bahl (1994), Marília Gomes dos Reis Ansarah (1993), Alexandre Panosso Netto (2005), Carlos Alberto Tomelin (2001) e Doris Van de Meene Ruschmann (1994).

Atualmente, Mário Carlos Beni é aposentado como professor titular da ECA/USP e atua como professor convidado de diversos programas de mestrado e doutorado, tanto no Brasil como no Exterior (Skoob, 2012) dando continuidade em suas atividades acadêmicas e em especial, desenvolvendo pesquisas e estudos sobre o turismo.

A seguir, serão apresentadas as principais publicações de Mário Carlos Beni sobre o turismo.

\section{BENI - PRINCIPAIS PUBLICAÇÕES SOBRE TURISMO}

Mário Carlos Beni é autor de livros que instigam debates e suscitaram estudos aprofundados sobre diversos temas inerentes ao fenômeno do turismo. Ele proporcionou o despertar em muitos indivíduos para o estudo sistêmico e crítico sobre a área. Dentre suas obras mais relevantes estão: Análise Estrutural do Turismo (1988); Globalização do Turismo: Megatendências do Setor e Realidade Brasileira (2004); Política e Planejamento de Turismo no Brasil (2006); e Colecionando Destinos: Viagens, Percepção, Imaginário e Experiências (2007).

3 Idem 1. 
Dentre essas obras, o livro "Análise Estrutural do Turismo" foi sinalizado pelo próprio Beni em seu currículo lattes como sendo uma de suas produções mais relevantes para o estudo do turismo. Assim, expõem-se no Quadro 1, de maneira geral, quais discussões as obras do autor trazem para o cenário turístico:

Quadro 1: Obras de Mário Carlos Beni

\begin{tabular}{|c|c|c|}
\hline $\begin{array}{c}\text { Capa da } \\
\text { publicação }\end{array}$ & Título & Descrição \\
\hline 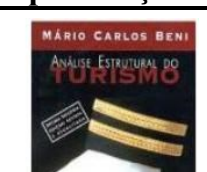 & $\begin{array}{l}\text { "Análise Estrutural do } \\
\text { Turismo" (1988) }\end{array}$ & $\begin{array}{l}\text { Nesta obra, Beni apresenta, interpreta e explica o fenômeno } \\
\text { do Turismo baseado na Teoria Geral dos Sistemas de Ludwig } \\
\text { Bertalanffy. No livro, Beni detalha o modelo referencial para } \\
\text { o "Sistema de Turismo" - o SISTUR. }\end{array}$ \\
\hline 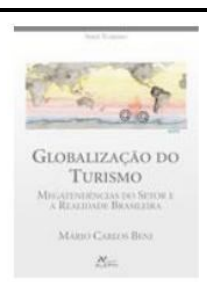 & $\begin{array}{l}\text { "Globalização do Turismo: } \\
\text { Megatendências do Setor } \\
\text { Realidade Brasileira" (2004) }\end{array}$ & $\begin{array}{l}\text { Nesta obra, Beni contextualiza e mapeia o campo da pesquisa } \\
\text { em turismo, destacando a recente história da pesquisa em } \\
\text { turismo no Brasil. }\end{array}$ \\
\hline 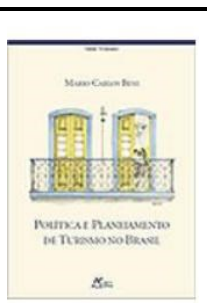 & $\begin{array}{l}\text { "Política e Planejamento de } \\
\text { Turismo no Brasil" (2006) }\end{array}$ & $\begin{array}{l}\text { A obra trata sobre a gestão do turismo e questões como o } \\
\text { desenvolvimento endógeno e mobilização social, participação } \\
\text { comunitária e empoderamento, empreendedorismo e gestão } \\
\text { territorial participativa. }\end{array}$ \\
\hline 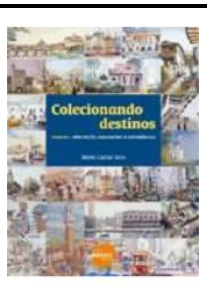 & $\begin{array}{l}\text { "Colecionando Destinos: } \\
\text { Viagens, Percepção, } \\
\text { Imaginário e Experiências" } \\
\text { (2007) }\end{array}$ & $\begin{array}{l}\text { Na obra, Beni relata seus } 40 \text { anos de viagens descrevendo } \\
\text { suas percepções e enaltece o fascínio pelas descobertas } \\
\text { inerentes ao ato de viajar. }\end{array}$ \\
\hline 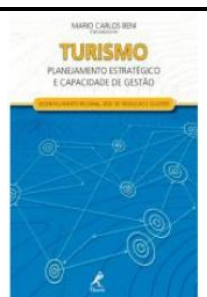 & $\begin{array}{l}\text { "Turismo: planejamento } \\
\text { estratégico e capacidade de } \\
\text { gestão - desenvolvimento } \\
\text { regional, rede de produção e } \\
\text { clusters" (2012) }\end{array}$ & $\begin{array}{l}\text { A obra traz propostas para a organização e articulação do } \\
\text { turismo ao longo de seus eixos conceituais, cadeias produtivas } \\
\text { e clusters que reúnem novas configurações de serviços e } \\
\text { produtos. A obra é dividida em três partes: politicas públicas e } \\
\text { planejamento dos espaços turísticos, sustentabilidade, e } \\
\text { instrumento de apoio ao planejamento. }\end{array}$ \\
\hline
\end{tabular}

Fonte: Dados da pesquisa, 2014.

No que tange aos artigos publicados pelo autor Beni, tem-se o quantitativo de 54 artigos publicados em periódicos, onde esses versam sobre planejamento turístico, gestão do turismo, globalização do turismo, competitividade, estudos sobre o SISTUR, turismo 
nacional, dentre outros, direta ou indiretamente relacionados ao planejamento e gestão do fenômeno turístico.

Ao selecionar no currículo Lattes, a opção ordem de importância disponibilizada no item ordenar por, do autor Beni, observou-se que os primeiros 27 artigos (que correspondem a $50 \%$ dos 54 artigos publicados em periódicos) tratam sobre Política e Planejamento; Comunicação; Competitividade turística; Turismo Nacional; Globalização do turismo; SISTUR; Formação e qualificação em turismo; e Turismo e Marketing 4 .

É possível perceber que o referido autor tem como foco de suas produções científicas o planejamento, a organização do turismo e a interação do turismo com as mais diversas áreas. A seguir se apresentará a contribuição dada por Mário Carlos Beni aos estudos do turismo.

\title{
4. CONTRIBUIÇÃO DE MÁRIO CARLOS BENI PARA OS ESTUDOS DO TURISMO
}

Com relação às contribuições dadas por Mário Carlos Beni aos estudos do turismo, expressas em suas obras, destaca-se o livro "Análise Estrutural do Turismo". A referida obra traz a análise do setor turístico brasileiro e representa uma contribuição que favorece aos profissionais que trabalham no setor, haja vista a necessidade de estudos científicos que auxiliem o desenvolvimento dessa área a partir da relação teoria e prática.

Nesse sentido, é válido esclarecer que para Beni (1998, p. 37) o turismo é um:

\begin{abstract}
elaborado e complexo processo de decisão sobre o que visitar, onde, como e a que preço. Nesse processo intervêm inúmeros fatores de realização pessoal e social, de natureza motivacional, econômica, cultural, ecológica e científica. Que ditam a escolha dos destinos, a permanência, os meios de transportes e o alojamento, bem como o objetivo da viagem em si para a fruição tanto material como subjetiva dos conteúdos de sonhos, desejos, de imaginação projetiva, de enriquecimento existencial histórico-humanístico, profissional, e de expansão de negócios. Esse consumo é feito por meio de roteiros interativos espontâneos ou dirigidos, compreendendo a compra de bens e serviços da oferta original e diferencial das atrações e dos equipamentos a ela agregados em mercados globais com produtos de qualidade e competitivos.
\end{abstract}

Diante do entendimento do que seria turismo na visão do autor, elucida-se que o mesmo, em seu livro, apresenta o Sistema de Turismo (Sistur) como um instrumento fundamental na contribuição para o aperfeiçoamento de políticas governamentais e privadas

\footnotetext{
4 Idem 1. 
de turismo. Revela, ainda, a importância do planejamento no processo de desenvolvimento do turismo com a sociedade, a economia e a política.

Vale enfatizar que o Sistur é considerando um sistema aberto que realiza trocas com o meio onde está inserido, e que por essa razão é interdependente (Beni, 1998). Nessa perspectiva o autor revela que o sistema pode ser entendido como um conjunto de partes que interagem para atingir determinado objetivo, destacando ainda que a elaboração do sistema possibilita uma visão do todo, ao invés de somente as partes.

Nesse sentido, para Beni (1998, p. 23):

Pode-se definir sistema como um conjunto de partes que interagem de modo a atingir um determinado fim, de acordo com um plano ou principio; ou conjunto de procedimentos, doutrinas ideias ou princípios, logicamente ordenados e coesos com intenção de descrever, explicar ou dirigir o funcionamento de um todo.

Sendo assim, tem-se que no sistema os diferentes aspectos (ambientais, políticos e mercadológicos) do turismo são considerados e apresentados de forma relacionada. Isso significa que as dimensões que constituem o setor não devem ser analisadas isoladamente, haja vista sua complementaridade para um desenvolvimento sustentável da atividade em um destino.

Desse modo, o objetivo do Sistur, segundo Beni (1998, p. 47) é:

Organizar o plano de estudos da atividade de turismo, levando em consideração a necessidade, há muito tempo demonstrada nas obras teóricas e pesquisas publicadas em diversos países, de fundamentar as hipóteses de trabalho, justificar posturas e princípios científicos, aperfeiçoar e padronizar conceitos e definições, e consolidar condutas de investigação para instrumentar análises e ampliar a pesquisa, com a consequente descoberta e desenvolvimento de novas áreas de conhecimento em turismo.

Assim, a atividade turística segundo a ótica de Beni se constitui em partes que interagem impactando umas as outras e que se bem planejadas e geridas podem levar ao seu desenvolvimento sustentável. Desse modo, a figura 1 apresenta o Sistur proposto por Beni: 
Figura 1: Sistur de Beni

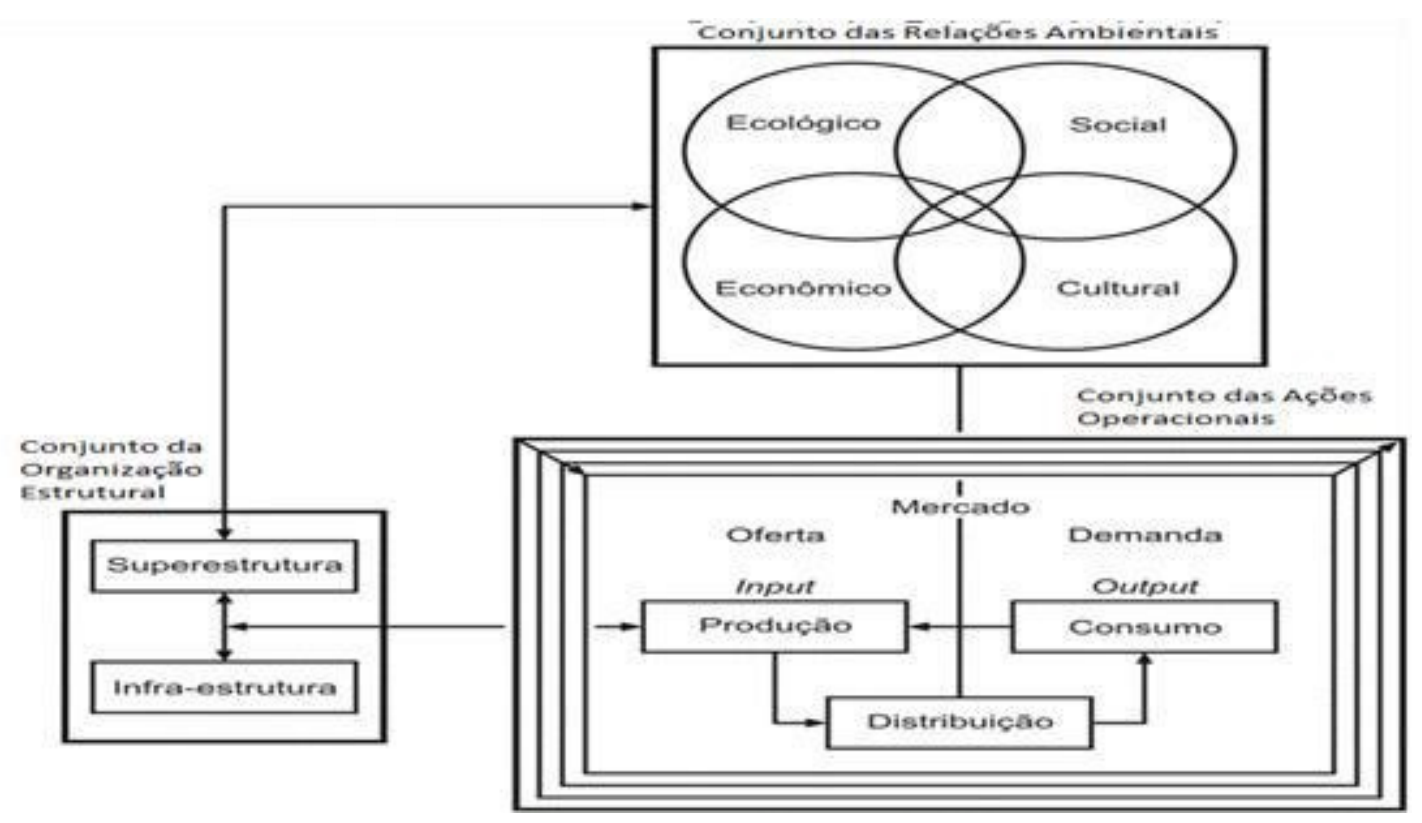

Fonte: Beni, 1998.

O Sistur é composto por três conjuntos: Conjunto das Relações Ambientais (CRA); Conjunto da Organização Estrutural (COE); e Conjunto das Ações Operacionais (CAO), onde cada um desses possuem seus subsistemas, como pode ser observado na figura 1.

De modo geral, Lohmann e Panosso Netto (2008) destacam que:

- $\quad$ O CRA mostra a íntima relação entre o turismo e o ambiente ao qual o mesmo se insere. Ou seja, mostra a influência que o ambiente econômico, social, ecológico e cultural tem sobre o turismo e a execução de suas atividades, bem como a influência que o turismo tem sobre esses ambientes.

- $\quad$ O COE reúne a superestrutura que inclui as políticas e diretrizes que visam regular o desenvolvimento da atividade turística, assim como a infraestrutura (básica, turística e de apoio) necessária para o bem estar dos residentes e dos turistas nos destinos onde o turismo está sendo implementado.

- $\quad \mathrm{O}$ CAO, por sua vez, é o conjunto que expressa os aspectos mercadológicos do turismo, ou seja, mostra a relação de oferta/produção (bens e serviços) e demanda/consumo (pessoas que possivelmente venham a consumir os bens e serviços ofertados) em um mercado onde ocorre a interação dessa oferta e demanda, bem como distribui os bens e serviços para aqueles que desejem adquiri-los/consumi-los. 
Em síntese, Beni enaltece que o turismo deve ser estudado e planejado holisticamente, ou seja, devem-se visualizar todos os elementos que compõe o sistema e não somente as partes dele. Assim, acredita-se que o turismo possa alcançar sua sustentabilidade.

Com esta visão e reconhecendo a existência de outros autores que propuseram um sistema de turismo como Cuervo (1967), Leiper (1979) e Molina (1994)? Mário Carlos Beni é considerado o autor que melhor explicou a atividade turística por meio de um modelo referencial e sistemático, o Sistur. Destacando que esse sistema foi aceito pela comunidade científica, sobretudo a brasileira e que, devido à disso, constitui o paradigma vigente do turismo (sistêmico), servindo como base para estudos futuros.

Logo, diante das informações apresentadas torna-se pertinente esclarecer que a obra de Beni apresenta o setor turístico de forma clara, já que esse leva em consideração os elementos que se encontram envolvidos no desenvolvimento da atividade turística.

Vale ressaltar frente à consideração de que o turismo é um sistema composto por partes indissociáveis, fato proposto por Beni (1998), alguns autores que foram influenciados de alguma maneira pelos estudos do autor, tais como: Alexandre Panosso Netto, Doris Van de Meene Ruschmann, Luiz Gonzaga Godói Trigo, Miguel Bahl, Carlos Alberto Tomelin, dentre outros, quer fossem seus orientandos ou não. Isso evidencia a aceitação da comunidade científica quanto à forma de estudo do turismo (Sistur), bem como se tem a constituição do paradigma sistêmico com a maioria de adeptos.

Visando enaltecer a aceitação e a presença da obra central de Beni - Análise Estrutural do Turismo em artigos científicos, investigou-se em quatro revistas brasileiras de turismo, no meio eletrônico, duas com fator de impacto B1 e as demais B2, a presença da obra do referido autor.

É importante ressaltar que para tal investigação foram considerados os anos 2006, 2009 e 2012, tendo um intervalo de três anos entre as publicações, com exceção da Revista Brasileira de Pesquisa em Turismo*, pois para essa, foram considerados os anos 2007, 2009 e 2012, dada a inexistência da publicação online no ano de 2006, como pode ser observado no Quadro 2: 
Quadro 2: Revistas Brasileiras de Turismo B1 e B2 (citação da obra central de Beni).

\begin{tabular}{|c|c|c|c|c|}
\hline \multirow[t]{2}{*}{ Revista } & \multirow[t]{2}{*}{ Qualis Capes } & \multicolumn{3}{|c|}{$\begin{array}{l}\text { Quantidade de artigos os quais a obra Análise } \\
\text { Estrutural do Turismo é citada/por ano de } \\
\text { publicação }\end{array}$} \\
\hline & & 2006 & 2009 & 2012 \\
\hline $\begin{array}{c}\text { Caderno Virtual de } \\
\text { Turismo }\end{array}$ & B1 & 6 & 6 & 1 \\
\hline $\begin{array}{c}\text { Revista Turismo em } \\
\text { Análise }\end{array}$ & B2 & 4 & 6 & 4 \\
\hline \multirow[t]{2}{*}{ Revista Turismo Visão } & \multirow[t]{2}{*}{ B2 } & 3 & \multirow[t]{2}{*}{3} & \multirow[t]{2}{*}{3} \\
\hline & & TOTAL: 13 & & \\
\hline \multirow{2}{*}{$\begin{array}{l}\text { Revista Brasileira de } \\
\text { Pesquisa em Turismo* }\end{array}$} & \multirow{2}{*}{ B1 } & 2007 & \multirow{2}{*}{3} & \multirow{2}{*}{1} \\
\hline & & 1 & & \\
\hline \multicolumn{2}{|c|}{ TOTAL } & 1 & 18 & 9 \\
\hline
\end{tabular}

Fonte: Dados da pesquisa, 2014.

É possível perceber, a partir do quadro 1, que a obra central de Beni, encontra-se presente em todos os anos de publicações investigados, ou seja, em cada volume e número das revistas encontram-se pelo menos 1 artigo que cita a obra do autor. Tais artigos, em sua maioria discutem sobre planejamento turístico, Análise Strenghts (Forças), Weaknesses (Fraquezas), Opportunities (Oportunidades) e Threats (Ameaças) (SWOT), Gestão Participativa, Políticas Públicas, dentre outros assuntos também trabalhados por Beni em suas obras.

Como contribuição para o conteúdo desse artigo, tem-se informações obtidas mediante entrevista realizada por Panosso Netto (2005) com Mário Carlos Beni. Assim, quando Beni foi questionado sobre o porquê de acreditar que a visão sistêmica seria melhor para o estudo do turismo, o mesmo respondeu que em sua prática docente sentia a dificuldade de seus alunos em entender a complexidade do fenômeno turístico, ou seja, suas relações e interrelações. Desse modo, o autor começou a desenhar diagramas cujo intuito era explicar tal complexidade a seus alunos.

Diante disso, após ter acesso à obra Análise de sistemas em geografia obra de Chistofolleti (1979 como citado em Vale, 2012), que aplicava a Teoria Geral de Sistemas aplicada a Geografia, Beni começa a desenvolver um pensamento sistêmico. Pensamento esse que tem como resultado o desenvolvimento do Sistur. Destaca-se que, inicialmente, Beni não 
estava preocupado com o fator metodológico do Sistur, mas sim em explicar a seus alunos o fenômeno turístico.

Assim, mais tarde, Beni amadureceu seus estudos quanto ao Sistur, realçando a existência de conjuntos e subsistemas na distribuição dos elementos que compõe a atividade turística, em sua tese de doutorado. Nesse sentido, vale destacar que o autor levou 10 anos para escrever o livro "Análise Estrutural do Turismo", tendo em vista que esse se originou de sua tese sobre o Sistur, e tinha como intuito ser suporte para a pesquisa e entendimento de estudantes sobre a complexidade turística (Panosso Netto, 2005).

Desse modo, entende-se que o desenvolvimento do Sistur facilitou não somente o entendimento dos alunos de Beni quanto às relações e inter-relações do turismo com o ambiente, as políticas, o mercado e outros. Mas também contribuiu para os estudos que se tem atualmente, que buscam trabalhar e entender o turismo como um sistema composto por partes que se integram para um determinado fim, ou seja, o desenvolvimento turístico.

A fim de tornar este estudo mais consistente, elaborou-se um questionário que foi encaminhado para os seguintes autores: Doris Ruschmann e Luiz Gonzaga Godói Trigo. Salienta-se que a escolha dos autores, para responder o questionário, foi feita em virtude dos mesmos terem sido alunos de Beni e carregarem, portanto, influências dos ensinamentos do referido autor.

As questões foram elaboradas a partir de uma pesquisa feita no Curriculum Lattes de Mário Carlos Beni, momento em que foi possível verificar quais as frequentes discussões do autor quanto ao estudo do turismo.

Em se tratando dos questionamentos realizados no questionário, esses buscaram identificar qual a opinião dos autores, Ruschmann e Trigo, no que se refere aos livros e aos artigos produzidos por Beni, que mais contribuíram e/ou contribuem para o estudo do turismo. Além do mais, ainda questionou-se quais autores, na visão de Ruschmann e Trigo, foram influenciados pelos estudos de Beni, acerca do turismo.

É pertinente esclarecer que o questionário foi encaminhado via e-mail, tendo sido respondido e retornado aos pesquisadores por meio da mesma ferramenta.

Nesse sentido, na pesquisa realizada em 2012 com Doris Van de Meene Ruschmann, questionou-se a opinião da autora, sobre quais dos livros de Beni apresenta maior contribuição para o estudo do turismo? Ruschmann respondeu: “Análise Estrutural do Turismo, pois engloba e analisa todos os aspectos da atividade turística". Desse modo, confirma-se a importância dessa obra e a proposta do Sistur para o estudo do turismo no momento presente e para o embasamento de estudos futuros. 
Ainda na entrevista supracitada, ao questionar sobre os autores que em sua opinião sofreram influência pelos estudos de Beni, Ruschmann (2012) respondeu: Miriam Rejowsky, Luiz Gonzaga Godói Trigo, Beth Wada, Carlos Alberto Tomelim, Doris Van de Meene Ruschmann, dentre outros. Nota-se que a autora confirma a informação apresentada nesse artigo quanto aos autores que receberam influência de Beni, por serem seus orientandos ou mesmo por compactuar com sua visão sistêmica.

Essa mesma pesquisa foi realizada com Luiz Gonzaga Godoi Trigo e as respostas obtidas aos questionamentos foram as seguintes: Ao questionar Trigo (2012) sobre sua opinião a respeito de quais dos livros de Beni apresenta maior contribuição para o estudo do turismo, o mesmo respondeu:

O livro fundamental de Mário Beni é Análise Estrutural do Turismo, publicado pela editora Senac São Paulo, em 1998 e teve várias edições. Foi o primeiro grande livro publicado no Brasil analisando o turismo como um fenômeno em todas as suas facetas, articulações e complexidades.

Desse modo, percebe-se que Trigo assim como outros autores da área do turismo, considera que a obra principal e de maior relevância de Beni, para o estudo do turismo primeiramente, é o livro “Análise Estrutural do Turismo”, por ser uma obra que propiciou um estudo de forma mais ampla do fenômeno.

Trigo (2012) ainda ressalta que entrou "no Senac São Paulo em 2005, e deu um parecer favorável à editora Senac SP sobre a publicação do livro. A dúvida era o tamanho da obra, o que encarecia a publicação. A editora bancou o texto e ele foi um dos mais vendidos". Ainda de acordo com Trigo (2012):

Outro livro importante é Colecionando destinos - percepção, imaginários e experiências (São Paulo: Senac, 2007), onde Beni fala de suas viagens pelo mundo. Através de suas 550 páginas, estão países, cidades, comidas, cenários e vivências relatadas com precisão cronológica e geográfica.

Percebe-se que além do livro "Analise Estrutural do Turismo", Trigo considera também como importante e relevante o livro Colecionando Destinos, uma vez que esse relata as experiências de Beni em suas viagens, e dessa forma mostra a realidade a qual se insere o turismo, desde a decisão de se viajar até o usufruto dos serviços turísticos.

Quando se questionou sobre os artigos produzidos por Beni, Trigo salientou que Beni publicou alguns na Revista Turismo em Análise, geralmente relacionado à sua obra Análise Estrutural do Turismo (Trigo, 2012). Nesse sentido, nota-se o empenho de Beni em 
desenvolver ainda mais pesquisas e trabalhos sobre sua teoria sistêmica - análise do turismo utilizando-se o Sistur.

$\mathrm{Na}$ opinião de Trigo, os autores que sofreram influência pelos estudos de Beni referentes ao turismo, foram Maruschca Moesh (hoje na UnB, em Brasília), Panosso Netto (hoje na EACH-USP), Renê Correa do Nascimento (falecido em 2012), dentre outros (Trigo, 2012). Ainda com relação aos autores que sofreram influência dos estudos de Beni, de acordo com Trigo (2012):

São tantos (as) que fica difícil enumerar. Basta lembrar que a ECA-USP foi responsável pela titulação do maior número de mestres e doutores do Brasil, na área de turismo e Beni foi um dos principais orientadores, ao lado de Mirian Rejowski, Dóris Ruschmann e Sarah Bacal.

Nota-se que Mário Carlos Beni influenciou a maioria dos seus orientandos, quando era professor na USP, ao propor o estudo do turismo com base no Sistur.

No que tange aos artigos produzidos por Mário Carlos Beni, nota-se que maior parte dos apresentados no seu Curriculum Lattes versa sobre o planejamento, gestão, políticas de turismo, dentre outros. Nesse sentido, dentre os artigos do autor, teve-se acesso a dois deles, que são: (1) Dimensão e Dinâmica de Clusters no Desenvolvimento Sustentável do Turismo; e (2) Política e estratégia do Desenvolvimento Regional: Roteiro Metodológico com Base na Instrumentação e Operacionalização do SISTUR - Sistema de Turismo Aplicado ao Projeto Costa Oeste - Estudo de Caso.

Em se tratando do primeiro artigo (1), tem-se em discussão a existência de Clusters, esses que de acordo com Beni (2003) seriam um conjunto de atrativos com destacado diferencial turístico. $\mathrm{O}$ autor, no referido artigo, ainda enaltece que o turismo não é uma manifestação isolada, pois as áreas do meio ambiente natural, cultural, e artificial, da vida pessoal e organização social se coligam.

Ressalta-se, em síntese, que o artigo discorre sobre a importância de se desenvolver um planejamento estratégico de marketing para o destino, a partir da identificação dos pontos favoráveis que o destino possui; criar um entorno competitivo com base na elaboração de uma política sólida; e ainda buscar por uma gestão estratégica do turismo, levando em consideração a abordagem política, o planejamento e a administração como bases para as respostas de mal uso dos recursos naturais e humanos no turismo.

Já no segundo artigo (2), Beni (1999) propõe a aplicação do Sistur ao Projeto Costa Oeste. Costa Oeste é o nome dado à região a qual se encontra o Lago Itaipu extremo Oeste do Paraná. De modo geral, o Projeto Costa Oeste aborda questões relacionadas à agricultura, ao meio ambiente, ao turismo e outros que consolidam outros projetos já existentes no local. 
Tendo como objetivo viabilizar a visitação a Itaipu e ampliar a permanência dos turistas na região.

Dessa forma, para o planejamento estratégico e integrado do desenvolvimento sustentável do turismo, propõem-se estudos preliminares; diagnóstico e prognóstico considerando os operadores do Sistur: Subsistema Ecológico (implementação de programas de proteção da fauna e flora, água, solo, etc.); Subsistema Econômico (geração de emprego e renda, etc.); Subsistema Cultural (superestrutura - identificação dos agentes públicos e privados do projeto, conhecimento de projetos etc., infraestrutura - melhorias nas vias de acesso, saneamento básico, abastecimento etc.); Subsistema do Mercado (estudo do fluxo de turistas, demanda de alojamentos e serviços, etc.); Estratégia de marketing - trabalhar a vantagem competitiva dos clusters (conjuntos de atrativos com destacado diferencial turístico).

O autor finaliza seu artigo, enaltecendo o papel da participação e envolvimento dos vários agentes no processo de planejamento do turismo, bem como a necessidade de um agente estratégico que viabilize a execução da atividade turística nos destinos (Beni, 1999).

Como pode ser observado, Mário Carlos Beni tem focado seus estudos na pesquisa sobre o planejamento, gestão e políticas de turismo, tendo em vista a importância da sustentabilidade na atividade turística nas mais diversas localidades. Assim, a maior contribuição de Beni para o estudo do turismo, sem dúvida, foi a elaboração do Sistur, esse que permitiu mostrar aos estudantes e também a outros estudiosos as relações do turismo com o ambiente e com outras atividades (econômicas, sociais, culturais, e outras).

Desse modo, tendo em vista localizar Mário Carlos Beni em uma fase de estudo, temse em um esquema desenvolvido por Panosso Netto (2007) em seu artigo intitulado Filosofía del Turismo: Una Propuesta epistemológica, publicado na Revista Estúdios e Perspectivas em Turismo, a seguinte representação (Figura 2): 
Figura 2: Esquema das fases de estudo do turismo

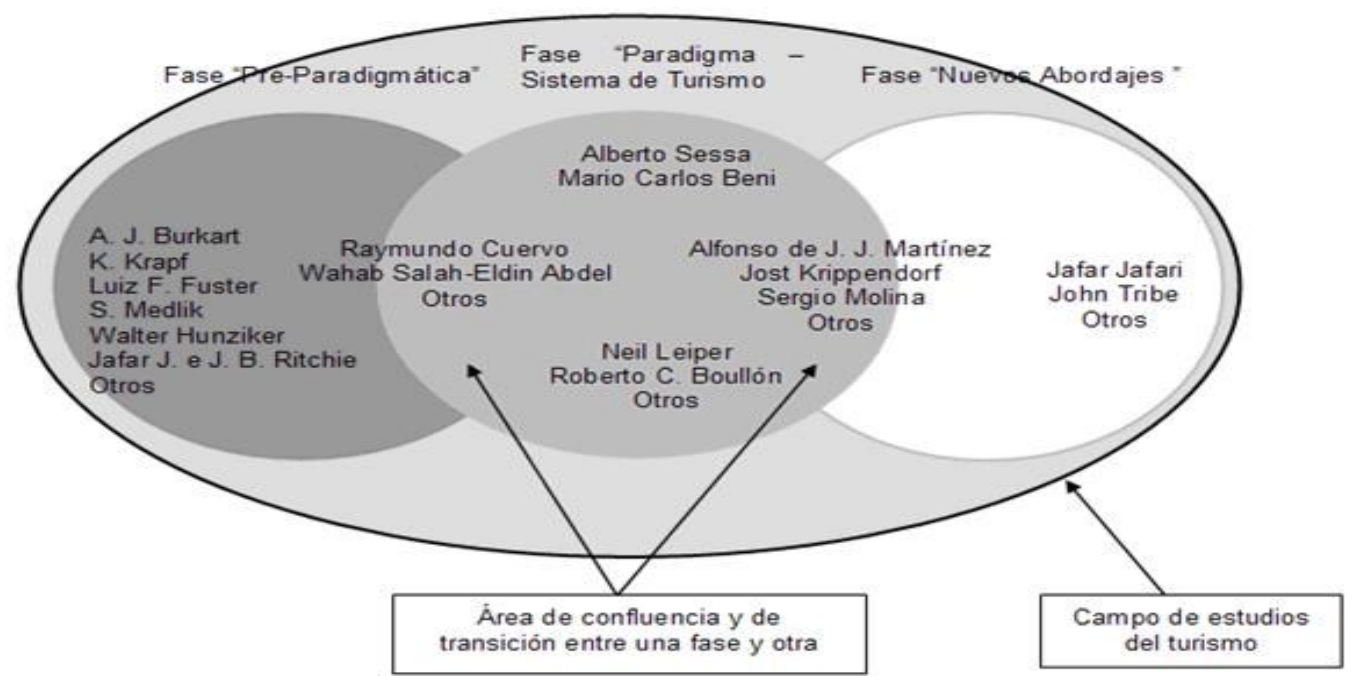

Fonte: Panosso Netto, 2007.

Nota-se no esquema de Panosso Netto, que Mário Carlos Beni encontra-se na fase paradigmática, ou seja, fase em que os autores estudam o turismo com base no paradigma sistêmico. Isso se confirma tendo em vista a linha de pesquisa e o pensamento de Beni, estarem voltados para planejamento do turismo considerando o Sistema de Turismo - Sistur como uma forma de estudar e entender o turismo e sua complexidade.

Mediante o exposto, é importante explicitar que conforme Beni (1990) foi a partir da década de 1950, que estudiosos introduziram ideias de sistemas, e passaram a exercer impacto ponderável, afetando todos os campos do conhecimento humano. Tal fato justifica as várias áreas do conhecimento voltadas à "abordagem sistêmica" ou "enfoque de sistemas".

Nesse contexto, o livro “Análise Estrutural do Turismo" trouxe uma apreciação do setor turístico brasileiro, o que representou uma contribuição que permitiu aos profissionais que trabalham no setor a entenderem a dinâmica da atividade. Já que a demonstração dos elementos que compõem o sistema relaciona teoria e prática de forma a demonstrar às trocas que ocorrem entre o turismo e o meio em que o mesmo está inserido.

Em função disso, o referido livro tornou-se leitura indispensável para os cursos superiores de turismo, pois o SISTUR foi apresentado como ferramenta importante para o aperfeiçoamento de políticas governamentais e privadas de turismo, que realça a pertinência do planejamento no processo de desenvolvimento da atividade juntamente com a sociedade, envolvendo ainda a economia e a própria política.

Desse modo, profissionais, estudiosos e alunos passaram a entender melhor a complexidade do fenômeno turístico, já que o modelo proposto por Beni veio a oferecer suporte para pesquisas na área e significativa compreensão de estudantes quanto à 
constituição do setor e acerca das inter-relações estabelecidas para fins do processo de desenvolvimento da atividade turística. Salienta-se que, em virtude dos destaques dados a tais inter-relações entre o meio ambiente, cultura, sociedade, entre outros, a economia, e ainda a demonstração de como funciona o setor mercadológico do turismo, a obra de Beni passou a influenciar na elaboração de currículos das universidades, permitindo que as partes que compõe o todo do turismo passassem a ser estudadas e investigadas para serem melhor desenvolvidas.

Assim sendo, vale esclarecer que com mais de trinta anos de magistério superior em turismo. Mário Carlos Beni foi o primeiro docente a ser autorizado pelo Ministério de Educação e Cultura a lecionar Teoria e Técnica de Turismo no País. Influenciando, portanto, o pensamento de outros autores do turismo e estimulando a crítica de estudantes da atividade quanto à importância de entender as dimensões que constituem o setor e a necessidade de se ter a visão do todo, em virtude da complementaridade para um desenvolvimento sustentável do turismo em um destino (Beni, 2014).

O modelo é utilizado, então, para representar à dinâmica e riqueza do sistema de turismo, permitindo que sejam identificadas e se conheça as variáveis que estão envolvidas no processo de desenvolvimento da atividade. O sistema proporciona ainda um ordenamento das inter-relações estabelecidas, demonstrando a função turística dessas, e permitindo a análise de cada uma delas a partir de uma visão holística.

Observa-se, portanto que, por meio do Sistur proposto por Beni, o turismo dispõe de um sistema e subsistemas interdependentes, no qual o profissional do turismo acaba por visualizar instrumentos para aperfeiçoar os setores da atividade de acordo com as necessidades específicas de cada localidade.

Acredita-se que dentre as contribuições do Sistur, a que demonstra que o turismo não é uma atividade isolada é de significativo destaque, haja vista a demonstração do envolvimento de elementos sociais e naturais na dinâmica da atividade e a influência de cada um deles no processo de desenvolvimento da mesma.

Outro ponto importante é o fato de que o Sistur apresenta a necessidade de se manter o setor mercadológico equilibrado de maneira que a oferta e a demanda estejam coerentes e sejam consistentes de modo a contribuírem para a economia local de um destino e até mesmo global.

Perante toda discussão, constata-se a importância do modelo sistêmico de Beni para o desenvolvimento do turismo brasileiro e também de estudos científicos na área. Bem como se compreende o Sistur como um instrumento que estimula profissionais, estudantes e curiosos a 
buscarem novas informações acerca de uma atividade complexa e dinâmica, estabelecida por meio de elementos interdependentes. Capaz de modificar e proporcionar benefícios a um destino, desde que seja analisada de forma holística e planejada para fins de atividade econômica e social em um destino.

\section{CONSIDERAÇÕES FINAIS}

Considerando os objetivos propostos neste artigo, tem-se que, por meio da pesquisa realizada, foi possível obter informações significativas sobre o autor Mário Carlos Beni, esse que versa sobre turismo e que é o foco deste estudo.

Sendo assim, com relação ao primeiro objetivo específico que trata da sistematização de informações relacionadas à vida e obra do autor, verificou-se que a vida acadêmica de Beni, como docente, iniciou-se no ano de 1971, quando esse passou a ministrar a disciplina recém-criada de turismo e desenvolvimento.

Ressalta-se, ainda, que com vasta experiência na área de turismo, o autor concentrou seus estudos nas seguintes linhas de pesquisa: planejamento e gestão para o turismo; planejamento e gestão das empresas de turismo e qualificação de recursos humanos para educação; e pesquisa em turismo. Nota-se que os estudos realizados pelo autor concentraramse na busca do incentivo ao desenvolvimento da atividade turística, tendo influenciado diversos estudiosos da área.

Nesse sentido, e em meio aos estudos realizados pelo autor, identificou-se que a principal obra de Mário Carlos Beni é o livro intitulado "Análise Estrutural de Turismo". Livro esse que fora sua maior contribuição para o estudo do turismo, por trazer o Sistur que permite estudar de forma sistêmica as relações do turismo com o ambiente econômico, social, cultural, ecológico, político, entre outros.

No que se refere ao segundo objetivo específico, que buscou identificar as principais publicações de Beni, voltadas ao estudo do turismo, encontrou-se as seguintes obras do autor e os respectivos anos de suas publicações: Análise Estrutural do Turismo (1998); Globalização do Turismo: megatendências do setor realidade brasileira (2004); Política e Planejamento de Turismo no Brasil (2006); e a obra Colecionando destinos: viagens, percepção, imaginário e experiências (2007). Já em se tratando de publicações em periódicos, constatou-se que o autor possui um quantitativo de 54 artigos publicados, esses que versam acerca do planejamento turístico, gestão do turismo, globalização do turismo, 
competitividade, estudos sobre Sistur, turismo nacional, dentre outros, sobre as questões que envolvem o planejamento e a gestão do fenômeno turístico.

Percebe-se, então, o significativo aporte teórico dado por Beni para aqueles que buscam conhecimento acerca da atividade turística, bem como intencionam desenvolvê-la em um destino.

Quanto ao terceiro objetivo específico, buscou-se investigar os principais autores que influenciaram e/ou foram influenciados pelos estudos de Mario Carlos Beni, em se tratando dos estudos na área do turismo.

Desse modo, foram identificados alguns autores que influenciaram Beni em seus estudos, como Ludwig Von Bertalanffy (autor do livro Teoria Geral de Sistemas), Raymundo Cuervo, Chistofolleti (entre outros), que contribuíram para a construção dos estudos referentes ao sistema de turismo elaborado pelo próprio autor. Assim como, os autores que foram influenciados por Beni em seus estudos, tais como Alexandre Panosso Netto, Doris Van de Meende Ruschmann, Luiz Gonzaga Godói Trigo, Miguel Bahl, Carlos Alberto Tomelim, pois foram alunos e/ou orientandos de Beni.

É importante elucidar que tais autores contribuíram/contribuem com estudos nas diferentes áreas do turismo, como epistemologia, políticas públicas planejamento e estudo de mercado, por exemplo.

Em se tratando do quarto e último objetivo específico, que pretendeu apontar as principais contribuições de Mário Carlos Beni para o cenário acadêmico do turismo, destacase que dentre seus aportes teóricos apresentados o de maior expansão no que se refere à divulgação é a obra “Análise Estrutural do Turismo". De tal modo, constatou-se que isso se deve ao fato de que a obra demonstra o turismo como uma atividade de envolvimento no que se refere aos elementos sociais e naturais da atividade, bem como em virtude da influência de cada um desses no processo de desenvolvimento da atividade.

Diante do exposto, acredita-se que de todas as contribuições de Beni que perduram e influenciam autores, professores, estudantes, e interessados pelo setor, a constatação de que o sistema turístico é um elo entre as relações ambientais (ecológico, social, econômico e cultural), as organizações estruturais (superestrutura e infraestrutura), e as ações operacionais (oferta e demanda) de um destino, são informações consistentes e que demonstram a complexidade da atividade e a pertinência de um planejamento que permita envolver tais elementos existentes, de forma a desenvolver um turismo sustentável, ou ainda, que seja capaz de beneficiar de forma equilibrada todos os setores inseridos neste processo. 
Em suma, destaca-se que a relação entre a teoria e a prática apresentada nos estudos de Beni acaba por esclarecer e instigar estudiosos na busca de entender de forma holística os elementos que fazem parte do turismo enquanto atividade econômica e social. Capaz de modificar um destino e trazer benefícios tanto positivos quanto negativos, dependendo da forma como o desenvolvimento do mesmo for tratado.

\section{REFERÊNCIAS}

Ansarah, M. G. R. (1993).. Estudo comparativo e perfil do agente cultural no Brasil e no México. Memorial da América Latina e Museu Nacional de Culturas Populares. 1993. Tese Doutorado. Escola de Comunicação e Artes, Ciência da Comunicação - Turismo. Universidade de São Paulo-USP, São Paulo,SP, Brasil.

Bahl, M.(1994). Legados étnicos na cidade de Curitiba: opção para a diversificação da oferta turística. Dissertação de Mestrado. Escola de Comunicação e Artes, Ciência da Comunicação - Turismo. Universidade de São Paulo, USP, São Paulo, SP, Brasil.

Beni, Mário Carlos. (1990). Sistema de Turismo - SISTUR: Estudo do Turismo face à moderna teoria de sistemas. Turismo em análise, 1(1).

Beni, Mário Carlos. (1998). Análise Estrutural do Turismo. São Paulo: SENAC/SP.

Beni, Mário Carlos. (1999). Política e Estratégia do Desenvolvimento Regional: Roteiro Metodológico com base na Instrumentação e Operacionalização do Sistur - Sistema de Turismo Aplicado ao Projeto Costa Oeste - Estudo de Caso. Turismo Visão e Ação, 2( 3), 51-70.

Beni, Mario Carlos. Globalização do Turismo: megatendências do setor e realidade brasileira. São Paulo: Aleph, 2004.

Beni, Mario Carlos. Política e Planejamento do turismo no Brasil. São Paulo: Aleph, 2006.

Beni, Mario Carlos. Colecionando Destinos: viagens, percepção, imaginário e experiências. Editora Senac São Paulo, 2007.

Beni, Mário Carlos. (2003). Dimensão e Dinâmica de Clusters no

Desenvolvimento Sustentável do Turismo. Estudos Turísticos. .

Beni, Mário Carlos. (2014). Currículo Lattes. Recuperando em 13 de junho, 2014 de http://buscatextual.cnpq.br/buscatextual/busca.do

Iganarra, R. L.(1998) Impacto do Turismo na Arrecadação de Impostos - Estudo de Caso Litoral Norte do Estado de São Paulo. Dissertação de Mestrado. Escola de Comunicação e Artes, Ciência da Comunicação - Turismo. Universidade de São Paulo, USP, São Paulo, SP,Brasil. 
Lohmann, G., Panosso Netto, A. (2008). Teoria do Turismo: conceitos, modelos e sistemas. São Paulo: Aleph.

Panosso Netto, A.(2005). Fenomenologia do Turismo: uma proposta de construção epistemológica. Tese de Doutorado. Escola de Comunicação e Artes, Ciência da Comunicação - Turismo. Universidade de São Paulo, USP, São Paulo, SP,Brasil.

Panosso Netto, A. (2005). Mário Carlos Beni Fala. In: TRIGO, Luiz Gonzaga Godoi (Org.). Análises Regionais e Globais do Turismo Brasileiro. São Paulo: Roca.

Panosso Netto, A. (2005). Filosofia do Turismo: teoria e epistemologia. São Paulo: Aleph.

Panosso Netto, A. (2007). Filosofîa del Turismo: Una propuesta epistemológica. Estudios y perspectivas en turismo, 16 (4), 389-402.

Publicações de Mário Carlos Beni. (2012). Recuperado em 12 de novembro, 2014, de http://www.mariocarlosbeni.com.br/interno/index.php?option $=$ com_content\&view $=$ article\&id $=5 \&$ Itemid $=28$

Ruschmann, D. V.M. (1994). O planejamento do turismo e a proteção do meio ambiente. Tese de Doutorado. Escola de Comunicação e Artes, Ciência da Comunicação - Turismo. Universidade de São Paulo- USP, São Paulo, SP, Brasil.

Skoob. (2012). Autores no Skoob. Recuperado em 13 novembro, 2014 de http://www.skoob.com.br/autor/7349-mario-ben

Tomelin, C. A.. O reposicionamento dos serviços do Agente de Viagens diante das tendências do mercado Catarinese. 2001. Dissertação de Mestrado. Universidade do Vale do Itajaí,- UNIVALI, Itajaí, SC, Brasil.

Vale, C. C. V. (2012). Teoria Geral do Sistema: histórico e correlações com a geografia e com o estudo da paisagem. Entre-Lugar, 3(6), p 85-108. 